\title{
E1 desconcertante reimpulso de la hegemonía internacional de Estados Unidos
}

Desde 1981 se ha extendido la idea de un incremento de la fortaleza económica, polftica y militar de Estados Unidos. Esta percepción es compartida en los países europeos, Japón, y en las naciones del Tercer Mundo. Ella es particularmente intensa cuando se observa desde América Latina.

Sorprende el cambio sustancial acaecido en los últimos años. Hasta 1980, se había generalizado la tesis de una declinación de la hegemonía norteamericana. Pocos años después prevalece la idea opuesta.

$\mathrm{La}$ tesis de una declinación surgió primero de los norteamericanos, quienes percibieron en la segunda mitad de la década del setenta que su país posefa una capacidad más limitada que en la postguerra para imponer sus políticas económicas y su voluntad en distintas regiones del mundo ${ }^{1}$.

La relación de Estados Unidos con América Latina mostraba también una evolución similar; el poder económico de América Latina en relación al de Estados Unidos había aumentado. Desde 1950 la región latinoamericana había adquirido un mayor margen de maniobra económico, tanto nacional como internacional. Su dependencia de la economía norteamericana mostraba una declinación, tanto en el terreno comercial como en el financiero y de la inversión extranjera directa. Asimismo, numerosos países habían ampliado y diversificado sus relaciones políticas y económicas².

A partir de 1982 la situación comenzó a variar. ¿Qué factores explican un cambio tan repentino y brusco en la situación prevaleciente? ¿Es un fenómeno estable o cíclico?

En las líneas que siguen intentamos analizar la naturaleza de los

${ }^{1}$ En relación a la hegemonfa norteamericana sobre América Latina, ver Abraham Lowenthal "The Us and Latin America: ending the hegemonic prehension", en Foreign Affairs, octubre 1976.

"Sergio Bitar, "United States-Latin American Relations. Change in economic power and implications for the future". Journal of Inter-American Studies and World Affairs. Vol. 26, No 1, febrero 1984. 
factores en juego, y evaluar las posibles tendencias de la economfa y la política internacional de Estados Unidos.

\section{La declinación hegemónica 1950-1980}

Estados Unidos asomó al término de la Segunda Guerra con una fortaleza indisputada sobre el resto del mundo. Esta situación comenzó a declinar progresivamente, tanto por el surgimiento económico de Europa y Japón como por el sustancial avance económico y militar de los países socialistas. Al mismo tiempo, se expandieron las economías del Tercer Mundo y se amplió considerablemente el espacio político para estos países, gracias a los procesos de liberación nacional y de descolonización.

Al término de la Segunda Guerra, la producción norteamericana representaba el 40 por ciento de la mundial. En 1970 esa cifra bajó al 25 por ciento, y en 1980 al 23 por ciento. En cuanto al valor agregado industrial, la participación de Estados Unidos a nivel mundial era del 57 por ciento en el año 1948, y se colocó en un 21 por ciento en 1980. Igual declinación se verificó en el comercio mundial. En 1948 las exportaciones norteamericanas fueron el 22 por ciento de las mundiales y en 1980 sólo un 11 por ciento. En cuanto a la producción de petróleo, en 1940 Estados Unidos generaba el 63 por ciento del total mundial. En 1950 esa cifra había bajado al 52 por ciento, en 1970 al 20 por ciento; y en el curso de la década última continuó declinando.

Los norteamericanos comenzaron a percibir la mayor competitividad económica de sus aliados occidentales y la mayor competitividad estratégica de sus adversarios militares. Los acontecimientos de Centroamérica, Afganistán, Polonia, Etiopía, Angola, Mozambique, Irán, la incapacidad para imponer un acuerdo en el Medio Oriente, fueron minando la confianza en el poder de Estados Unidos.

Una demostración palpable de este sentimiento fue la propia campaña de Reagan en 1980. Ésta se sustentó en la idea de que Estados Unidos había perdido importancia y que esa pérdida se debía a su debilitamiento militar y económico. La baja productividad, la escasa inversión, el aumento de las regulaciones, la pérdida de la iniciativa privada, la "pasividad" generada por el "welfare state" eran algunas de las causas que, a juicio de Reagan, debian atacarse ${ }^{3}$.

Esta sensación de vulnerabilidad también se propagó a las relaciones con América Latina. La deuda externa y la crisis financiera proyectaron alarma sobre el sistema financiero norteamericano. El advenimiento de los sandinistas al poder en Nicaragua, la crisis en El Salvador, incluso los acontecimientos de Granada antes de la

Ver SELA, Las relaciones económicas de América Latina con Estados Unidos, 1982-1983, Siglo xxr, México 1988. 
muerte de Bishop mostraban que Estados Unidos ni siquiera estaba en capacidad de controlar lo que ocurría en su "front yard".

\section{¿La recuperación hegemónica 1981-?}

Los hechos acaecidos desde 1982 provocaron desconcierto entre quienes argumentaban la declinación hegemónica y dieron origen a nuevos planteamientos.

Quienes hoy sostienen la tesis de una recuperación, señalan que Estados Unidos ha afirmado su capacidad de encuadrar a los demás países en un marco de política económica internacional ajustado a sus propios intereses. Conjuntamente, se afirma que se han soldado los intereses del capitalismo financiero internacional, bajo el comando de Estados Unidos.

Una segunda línea de argumentación de quienes sostienen que ha habido una recuperación hegemónica se refiere a la tecnología y la industria. Estados Unidos estaría modernizando su industria tradicional y retomando la delantera en la industria avanzada. Ese país sería el centro generador de un cambio sustancial de la división internacional del trabajo. Este cambio tecnológico sería portador de un ciclo expansivo largo, y no de una mera reactivación. Por último, se estaría gestando una creciente globalización de la economía mundial y Estados Unidos es la única economía con rango continental capaz de liderar ese proceso.

En suma, la modificación del sistema financiero internacional y la nueva división internacional del trabajo serían los pilares sobre los cuales se sustentarfa la fortaleza económica norteamericana y en ambos terrenos mantendría el liderazgo internacional ${ }^{4}$.

Quienes refutan estos puntos de vista sostienen, en primer lugar, que la economía norteamericana no ha elevado su peso relativo en la economía mundial. Actualmente, el producto de Estados Unidos representaría el 24 por ciento del total. mientras que en 1955 era el 40 por ciento, y para el año 2000 esta cifra llegaría apenas a un 18 por ciento. En segundo lugar, los detractores sostienen que la recuperación económica norteamericana, verificada en el período 1983-1984, es de carácter cíclico. La Reaganomics no sería más que una suerte de "Keynesianismo improductivo" financiado desde el exterior. El crecimiento sería artificial y se apoyaría en la extracción de recursos de otros países desarrollados y del Tercer Mundo, que no podría perdurar. Por último, también sostienen que no hay un "renacimiento tecnológico" en Estados Unidos".

'Una excelente argumentación se encuentra en el trabajo de Maria da Conceição Tavares, en este mismo libro.

"Michel Godet, "Etats Units: Renaissance ou declin caché?". Centre de Perspectives et d'Evaluation, Ministerio de la Industria y la Investigación. Mimeo, Paris, 1984. 
Sergio Bitar / El desconcertante reimpulso de la hegemonfa internacional...

Evidentemente, estamos en medio de un proceso complejo. Un juicio sobre la recuperación o declinación hegemónica requiere de un período más prolongado. Entretanto, es necesario explorar los factores que hoy, de manera nueva, afectan el poder económico de los Estados Unidos frente al resto del mundo.

El análisis de estos antecedentes, debe hacerse con una nueva perspectiva: está en gestación un nuevo ordenamiento y funcionamiento de la economía mundial, y las formas de ejercicio del poder global se han modificado. Mientras prevalecía una economía global con un grado de interdependencia bajo, las relaciones bilaterales poseían un carácter predominante y el poder relativo era ejercitado mediante la vinculación directa del país poderoso con cada uno de los demás.

A medida que se configura una economía global, con un alto nivel de interdependencia, el ejercicio del poder se verifica mediante la regulación del sistema económico mundial. Es en esta nueva realidad que la potencia norteamericana despliega su poder. En una economía integrada globalmente, las normas de regulación general son la clave para su funcionamiento $y$, por tanto, quien es capaz de establecer esas ñormas, por la vía consensual o imperativa, está en condiciones de ejercer el predominio.

Esta capacidad de ejecutar la regulación global no se sustenta sólo en factores económicos, también en factores militares. Por tanto, el análisis de la hegemonía económica supone una visión integrada de ambos aspectos, económico y de seguridad.

\section{Hegemonia norteamericana y encuadre de la economia global}

La manifestación más evidente del poder económico norteamericano ha sido la capacidad de imponer a los demás su propia política económica. A pesar de las consecuencias negativas, la Administración Reagan sostuvo y aún mantiene casi inalterable su curso de acción. ¿Puede sostenerse esta posición? ¿A qué se ha debido esta capacidad de imponer su política económica?

Diversos factores explican esta situación. El más importante es la configuración de un sistema financiero y comercial mundial bastante interdependiente. Nunca antes las políticas de un país condicionaron tanto las de los demás. Incluso los países de tamaño mediano, como los de Europa Occidental, vieron limitadas sus opciones por sus vecinos. Por ejemplo, la política inicial del gobierno de Mitterrand tuvo que ser revertida a poco andar. La expansión de las remuneraciones y el intento de reactivación provocó una fuga de demanda hacia Alemania Occidental, originando en Francia un fuerte desequilibrio en su balanza de pagos. Incluso dentro de la Comunidad Económica Europea, entre economías de tamaño simi- 
lar, la interdependencia hace muy difícil la adopción de medidas aisladas por parte de un país.

Progresivamente, se ha pasado de una economia internacional conformada por la superposición de economías nacionales a una economía internacional de carácter global. El nuevo sistema requiere de una función de regulación global. Esta es la función que ha venido desarrollando Estados Unidos y que ha logrado imponer sobre Ios demás.

No existe otra potencia capaz de llevar a cabo esta tarea. La cuestión central es si esa función puede ser cumplida unilateralmente, como lo fue en los últimos años, o si requerirá de una mayor coordinación, como era la tendencia a finales de los 70 .

Un conjunto de cambios en la estructura económica internacional ha permitido que Estados Unidos se coloque en una posición ventajosa.

E1 primero es Ia notoria expansión de las relaciones Norte-Norte, en desmedro de las relaciones Norte-Sur. En efecto, Estados Unidos ha incrementado sus vinculos comerciales con los países desarrollados. Las importaciones desde esos países se elevó del 51,2 por ciento del total en 1980 al 61,6 por ciento en 1984. Asimismo, las exportaciones de Estados Unidos a países desarrollados se elevaron del 59,2 por ciento en 1980 al 62,4 por ciento del total norteamericano en 1984.

Europa y Japón han acrecentado su importancia relativa para Estados Unidos. Igual cosa ha sucedido con la inversión extranjera directa norteamericana. En 1970, el stock de inversión extranjera directa de Estados Unidos en los demás países desarrollados alcanzaba cerca del 69 por ciento del total norteamericano, luego creció al 73,5 por ciento en 1980 para colocarse finalmente en el 75 por ciento en $1983^{6}$.

En el terreno financiero se aprecia una situación similar. A partir de 1982, cuando el riesgo de la banca norteamericana en América Latina alcanzó su mayor nivel, comenzaron a restringir significativamente sus colocaciones en la región. Esta baja fue compensada por una elevación de sus flujos financieros hacia países desarrollados y la ampliación de las colocaciones en el propio mercado norteamericano.

Estados Unidos también se transformó en un mercado atractivo para los demás países desarrollados. Japón ha elevado sus inversiones directas en el pais del Norte y ha incrementado apreciablemen-

"Los antecedentes sobre comercio se han obtenido de SELA, "Las relaciones comerciales de Estados Unidos con América Latina". Documentos internos, mimeo 1985 y los datos sobre inversiones extranjeras de: us Department of Commerce Selected Data on us Investment Abroad 1951-76, febrero 1982 y "us Direct Investment Abroad 1977-83, en Survey of Current Business, Washington, nov. 84. 
te la colocación de fondos en el mercado financiero de ese pais. En el último tiempo, Japón ha sido el principal adquirente de bonos del Tesoro de Estados Unidos. Igualmente, Europa ha canalizado recursos financieros hacia la economía norteamericana, ayudando a financiar el deficit fiscal.

Esta nueva situación le ha conferido a Estados Unidos un mayor poder de negociación con sus aliados de Europa y Japón. El incremento de las relaciones Norte-Norte ha concentrado aún más el poder en un núcleo que determina el funcionamiento de la economía mundial.

Un segundo rasgo de importancia es la cómoda posición relativa de la economía norteamericana frente a las demás economías desarrolladas. La posición japonesa ha venido creciendo sustancialmente y su influencia sobre el Sudeste Asiático ha acrecentado también el poder de esa nación. Conjuntamente, las economías de Japón y de los países del Sudeste Asiático adquirieron en 1984 una mayor gravitación para Estados Unidos que la Comunidad Económica Europea, por primera vez en la historia. Este mayor poder del Japón tiende a disminuir el poder relativo de Estados Unidos.

Sin embargo, a pesar del conflicto comercial y del impacto japonés sobre la industria norteamericana, se ha producido un acomodo entre ambas partes. Para Estados Unidos, el déficit comercial con Japón tiene como contraparte un enorme flujo financiero que le ayuda a solventar su déficit fiscal. Para Japón, la expansión de la economía norteamericana le ha permitido mantener ritmos de expansión importantes arrastrados por el crecimiento de sus exportaciones al mercado norteamericano. En 1985, el mercado de Estados Unidos representa aproximadamente el 30 por ciento del mercado mundial de exportaciones japonés. A su vez, para Japón resulta atractivo colocar sus excedentes financieros en un país que es percibido como de alta seguridad para los capitales.

Con todo, Japón se encuentra subordinado a la política norteamericana. Son dos los elementos centrales de tal subordinación. El primero, es la importancia del mercado norteamericano para la expansión de la economia japonesa. Para los japoneses constituye un peligro latente un mayor proteccionismo norteamericano. El segundo es de naturaleza militar, puesto que Estados Unidos asegura la integridad territorial del Japón en un eventual conflicto con la Unión Soviética en la zona del Pacífico.

Con Europa la situación ha cambiado. Esta región ha disminuido su importancia relativa para los Estados Unidos. Además la lenta recuperación europea, las elevadísimas tasas de desocupación y la aparente rigidez ("euroesclerosis") han debilitado la posición europea.

Esta realidad coloca a Estados Unidos en el centro de la escena, con Japón por un lado y Europa por el otro, ambos en posición su- 
bordinada. Estados Unidos puede erigirse así en árbitro de la economía internacional y su presencia es imprescindible para coordinar las políticas económicas de los países avanzados.

A esto se agrega un nuevo fenómeno: la disminución del ritmo expansivo de la economía soviética y de los países socialistas. En el período 1950-1976 la tasa de expansión soviética fue superior al 4,5 por ciento interanual; entre 1976 y 1980 fue del orden del 2,7 por ciento y en el período 1981-1984 bajó a cerca del 2 por ciento?

La presencia soviética en el comercio y las finanzas mundiales declinó en los últimos años. Este hecho, y cierto grado de autosuficiencia con que ha operado el área socialista en relación al resto de la economía mundial, le ha restado influencia económica. Ello ha favorecido a Estados Unidos, que ha acrecentado la suya.

Paralelamente, Estados Unidos ha tenido éxito en imponer su estrategia económica internacional. Su propósito es estructurar un sistema global regulado por normas e instituciones multilaterales e ir ajustando y extendiendo sus funciones. Ese pais ha tomado el liderazgo para conformar un sistema global financiero y monetario, de servicios, inversión extranjera directa, propiedad intelectual, innovación tecnológica, etc.

La idea-fuerza es montar un sistema de libre mercado que se implante primero en la OECD, y luego se extienda a las economías del Tercer Mundo8. Esta línea estratégica le permite afianzar su rol de líder. Un sistema estructurado sobre normas globales y sobre el principio de la libertad del mercado favorece al más poderoso. Con matices, los demás países desarrollados también coinciden con Estados Unidos en estas metas estratégicas. Las divergencias se verifican respecto a la posición relativa de cada uno.

Gabe preguntarse si estas tendencias proseguirán en el futuro. A mi juicio, el grado de predominio manifestado en estos años no perdurará de la misma forma. Es dudoso que se mantenga un ritmo de crecimiento alto en Estados Unidos. De no ser así, esa economía no tendrá el efecto "locomotora" que mostró en el pasado, ni podrá consitituirse en una "esponja mundial" capaz de absorber importaciones de todos los rincones del mundo.

Las economías europeas irán recuperando cierta dinámica y es posible que se materialicen modificaciones en sus estructuras que les permitan flexibilizarse y acelerar sus reacciones. Asimismo, podrían agilizarse los mecanismos de coordinación intraeuropeo.

TPadma Desai, "Technology transfer for mutual gain", The New York Times, febrero $10,1985$.

8Kenneth Dam, "Change and continuity: American Foreign Policy in the 1980's", Department of State Bulletin, us, Department of State, dic. 1984, pp. 70 74. Ver los documentos de la Administración Reagan contenidos en Sergio Bitar y Carlos Moneta, La politica económica de Estados Unidos hacia América Latina, Grupo Editor Latinoamericano, Buenos Aires, 1984. 
Japón y los países del Sudeste Asiático seguirán con un crecimiento continuo. Además, el Japón será un área cada vez más relevante del punto de vista del financiamiento internacional.

En cuanto a los países socialistas, es posible que comiencen a dar frutos algunas reformas económicas. En ciertas naciones de Europa Oriental ha tenido lugar un proceso de innovación, aunque por su tamaño relativo pesan poco en la economía mundial. Sin embargo, el caso chino es distinto. De provocarse una mayor apertura al exterior se modificará el mapa económico internacional. El advenimiento de Gorbachov puede significar también una modificación importante en las prioridades soviéticas. El ritmo de expansión futura de las economías avanzadas dependerá de la capacidad de innovación tecnológica y de gestión descentralizada. Ambos factores están siendo valorados más en la Unión Soviética9.

El poder hegemónico depende de la estructura del sistema. Mientras menos son los actores en la escena mundial con capacidad de determinar los acontecimientos globales, más fácil es la regulación y la concertación. Cuando los intereses de los grandes actores son relativamente coincidentes con la evolución de la situación general, tales actores cuidarán que la evolución de la totalidad del sistema sea relativamente aceptable para todos ellos.

Distinto es el caso cuando el número de actores se incrementa y cuando algunos tienen una incidencia muy secundaria en la evolución de los acontecimientos generales. Entonces, puede acontecer que los intereses de los grandes sean muy dispares con los de los pequeños y al sentirse éstos profundamente afectados tengan interés en perturbar el funcionamiento del sistema global, en vez de ajustarse a él.

Un grupo de países pequeños e incluso países medianos, puede pensar que obtienen más del sistema actuando en contraposición a los grandes países, aun cuando ello conlleve una alteración sustantiva en la regulación general ${ }^{10}$.

Para que una hegemonía perdure es imprescindible que se funde no sólo en la fuerza, sino en el consenso de las partes. De lo contrario, aumentan las tensiones entre los mayores y también pueden verificarse comportamientos disfuncionales de los medianos $y$ pequeños.

-Las declaraciones de Gorbachov a la revista Time son una clara ilustración al respecto. Gorbachov señala: "Sometimes we do not work well enough. We have not yet learned proper managerial skills as is required by a modern economy. The imperative or our time is to decisively improve this state of things. Large scale economic experiments are under way there. Time, sepbre. 9, 1985, página 14.

${ }^{10}$ Este punto ha sido extenso y brillantemente desarrollado en el libro de Mancur Olson, The Rise and Decline of Nations, The University Press, New Haven, 1982, pp. 47-49. 
Mi impresión es que en los años por venir Estados Unidos deberá elevar su concertación con los demás países desarrollados, deberá contemplar los intereses de los países del Tercer Mundo, y enfrentará una presencia más activa de países socialistas. Su función reguladora seguirá siendo dominante, pero más condicionada que en el pasado reciente.

\section{Hegemonia y control del sistema financiero internacional}

En el campo financiero el cambio ha sido más espectacular. Existe hoy un mercado de capitales integrado donde se movilizan enormes sumas. No sólo se ha elevado el financiamiento del comercio, mucho más importante ha sido la expansión del movimiento de capitales a escala mundial. Actualmente, el financiamiento necesario para operar el comercio y la inversión extranjera directa se estima en 2 millones de millones de dólares anuales ( 2 trillones en la nomenclatura norteamericana), mientras el movimiento de capitales alcanza a 50 millones de millones de dólares ${ }^{11}$.

Este sistema integrado necesita de un marco de coordinación y ese marco lo han proporcionado esencialmente los Estados Unidos y la banca norteamericana. Tres factores han facilitado esta tarea: la recuperación económica norteamericana, la fortaleza del dólar y la percepción de seguridad que otorga el mercado norteamericano ante riesgos políticos, económicos o militares.

La valorización del dólar ha creado una sensación de gran poder. Mientras en 1980 el índice respecto de las otras monedas era de 88,1, en febrero de 1985 alcanzó un máximo de 140,9, teniendo como base el período 1980-1982 con un valor de 10012. Incluso después de la devaluación de fines de 1985, aún permanece comparativamente alto. El dólar se constituyó nuevamente en la moneda internacional. Quien tiene la capacidad de emitir la moneda mundial, tiene un poder enorme sobre los demás. Estados Unidos recuperó, en buena parte, ese poder en el período 1981-1985.

Este cambio fue muy rápido. Hay que recordar que en la segunda mitad de los setenta estaba funcionando la Comisión Trilateral y se hablaba de la creación de una moneda mundial. Los derechos especiales de giro eran concebidos como una moneda que serviría al uso internacional y estaría respaldada por las economías más fuertes. Corrientemente se buscaba una canasta de monedas para asegurar el funcionamiento de las finanzas internacionales. Esta pre-

"William Eberle, Richard Gardner, Robert Feenstra, "Governance in a World Economy. The future of the International Economic System". Mimeo, Aspen Institute for Humanistic Studies, marzo 1984.

12Leonard Silk, "A true value of the dollar", The New York Times, julio 17 de 1985, p. đ2. Estos datos están basados en cálculos del Morgan Guaranty Trust, quien elabora un indice ligado a las 15 principales monedas ponderadas, por su comercio respectivo. 
ocupación se desvaneció en lá primera mitad de los ochenta. Cabe preguntarse sobre la permanencia de este cambio.

Una primera cuestión concierne a la firmeza de la recuperación económica norteamericana. Desde fines de 1984 se ha verificado una notoria declinación $y$, si bien se mantendrá un ritmo de crecimiento positivo, éste será bajo. Si así fụere, la percepción de su fuerza relativa podría alterarse.

Una segunda cuestión está vinculada a los desequilibrios básicos: el fiscal y el comercial. La línea dominante en la administración Reagan imagina una corrección graclual o "soft landing". La tasa de interés se reduciría lentamente, el dólar se devaluaría también con gradualidad, permitiendo una recuperación de las exportaciones, una disminución de las importaciones y del déficit comercial. Los cortes al gasto público reducirían el déficit fiscal, creando un marco más tranquilizante para el futuro.

Existe otro escenario, que podría calificarse de "crash landing". Tal sería el caso de una corrida contra el dólar y una caída más rápida de esa moneda. Los flujos de recursos externos podrían obstruirse, dificultando el financiamiento del déficil fiscal, con las repercusiones consiguientes sobre los Estados Unidos.

Si se piensa que la tasa de crecimiento de 1985 será de 2 por ciento para Estados Unidos y se observan las presiones enormes existentes en el Congreso de ese país para disminuir las importaciones (se han presentado del orden de 300 propuestas legales para proteger a determinadas industrias), se puede concebir un escenario con proteccionismo e incremento de las tasas de interés, que podría acarrear una disminución de las inversiones y una crisis todavía mayor en los países de América Latina. En suma, subsisten elementos de inestabilidad que no pueden desconocerse.

Otra cuestión principal es la deuda de Estados Unidos, que en 1985 pasó a ser un deudor neto frente al resto del mundo, por vez primera desde la Primera Guerra Mundial. Financiar la expansión con un endeudamiento masivo constituye una flaqueza de la recuperación norteamericana. Se ha mantenido una tendencia al consumismo alto y a un gasto militar y social también elevado.

No sólo el financiamiento macroeconómico ha tenido esta característica. También se observa un alto endeudamiento de corto plazo en las empresas. Las actividades industriales y comerciales de los Estados Unidos, presentaban en la década de los 50 una relación de 2,47 a 1 entre deuda de largo plazo y de corto plazo; esta cifra bajó a 2,18 a 1 en la década de los 60 . Actualmente es de 1 a $1^{13}$.

Algunos escenarios futuros calculados por el Morgan Guaranty

${ }^{13} F r e d$ Branfman, "Unexplored America: economic rebirth in a post industrial world", en World Policy Joutnal, otoño 1984, p. 49. 
Trust revelan que si el dólar mantuviera su valor actual respecto a las otras monedas y si no cambiaran las políticas económicas, Estados Unidos alcanzaría una deuda externa neta de cerca de 1 millón de millones de dólares en 1990, probablemente superior a toda la deuda externa del Tercer Mundo para ese año. Para sostener esa situación, Estados Unidos debería absorber cerca del 15 por ciento del ahorro mundial de todos los países no socialistas. En 1984, la absorción de ahorro mundial fue del 8 por ciento ${ }^{14}$.

Estados Unidos enfrenta una deuda interna y una deuda externa que necesita de una corrección profunda para mantener su capacidad de liderazgo a escala mundial. Esa corrección no es una tarea asegurada ni la forma en que se verifique será gradual. Existen elementos estructurales que hacen dificultosa esta tarea. Piénsese solamente que los intereses sobre la deuda pública alcanzan una cifra cercana al déficit fiscal. A medida que ese déficit se mantiene, se incrementa la deuda y consiguientemente sube el servicio de esa deuda, incrementando a su vez el déficit. Se trata de un círculo vicioso.

La situación de balanza de pagos también se ha modificado. A partir de 1982 emergió un déficit en la cuenta corriente de Estados Unidos de 9,2; 41,6 y 101,6 mil millones de dólares en 1982, 1983 y 1984 respectivamente. En el pasado, el déficit comercial era sobrepasado con creces por el excedente en la cuenta de servicios. Esta situación ha venido cambiando debido al vuelco en la posición acreedora neta de Estados Unidos. Buena parte de los ingresos en la cuenta de servicios provenían de las colocaciones de la banca norteamericana en el exterior, así como de los dividendos generados por la inversión extranjera de Estados Unidos. A medida que se ha revertido la situación y otros países han elevado sus colocaciones financieras y de inversión extranjera directa en la economía norteamericana, se ha generado una enorme salida por intereses y dividendos, dejando un saldo favorable a Estados Unidos mucho más pequeño que en el pasado, que no alcanza a cubrir el déficit en el comercio de bienes.

El déficit en la cuenta corriente ha sido compensado con un ingreso de capitales, mayor que en el pasado, y simultáneamente por una disminución de la salida de capitales norteamericanos al exterior. En efecto, tal salida disminuyó de 118,900 millones de dólares en 1982 a 49,500 millones en 1983 y a 21,200 millones de dólares en 1984. Inversamente, la entrada de capitales se elevó a partir del año 1980, cuando alcanzó 58,100 millones; fue de 92,500 millones en 1982; 81,700 millones en 1983 y 92,800 millones en $1984^{15}$. Tam-

\footnotetext{
${ }^{14}$ Morgan Guaranty Trust, World Financial Markets, New York, marzo-abril 1985. Guadro 1 , escenario A. Para las cifras relativas al porcentaje del ahorro absorbido por Estados Unidos, ver p. 5 .
} 
bién aquí se genera un círculo vicioso, en cuanto el déficit de la cuenta corriente requiere de nuevos ingresos de capital y esos nuevos ingresos generan a su vez nuevas salidas por concepto de intereses, afectando negativamente la cuenta corriente de la balanza de pagos.

Algunos críticos asimilan con ironía el crecimiento norteamericano reciente a las experiencias del Sur de América, es decir, una expansión sustentada en endeudamiento, sobrevaluación de la moneda, déficit comercial y debilitamiento de la capacidad productiva.

Con todo, preciso es reconocer que un país que emite la moneda internacional dispone de distintos expedientes para resolver el problema de su endeudamiento externo, que van desde la inflación internacional a una devaluación de su moneda o a otros mecanismos compensatorios que reduzcan sus pasivos con el exterior, en términos relativos a la economía real.

Por los antecedentes expuestos concluyo que declinará la posición detentada por Estados Unidos en el sistema financiero internacional. Además, Japón incrementará su papel financiero internacional. En los últimos años ha aumentado apreciablemente sus colocaciones en el mercado mundial y está extendiendo su sistema financiero para mejorar su presencia internacional. Simultáneamente, los europeos irán perfeccionando su capacidad de coordinación y, en la medida que sus economías se reactiven, sus monedas serán más gravitantes en el sistema financiero internacional. Su moneda (ECU) es utilizada crecientemente. De ser así, Estados Unidos se verá obligado a elevar su coordinación con los otros países desarrollados y tomar en cuenta con más cuidado sus intereses ${ }^{16}$.

Del análisis se aprecia una desproporción entre la hegemonía de Estados Unidos en el campo financiero y su menor fuerza relativa en la economía productiva y en el comercio internacional. Pienso que magnificar la importancia de los aspectos financieros, sin considerar la base productiva y la menor gravitación norteamericana en el producto, la inversión y el comercio mundiales, puede ser errado, porque al final de cuentas es sobre aquella base económica que se apoya y proyecta la capacidad de regulación de la economf́a mundial.

\section{Hegemonia, base productiva y capacidad tecnológica}

La economía norteamericana continuará siendo la más fuerte en el futuro previsible. Su producto nacional bruto es 2,7 mayor que

\footnotetext{
${ }^{15}$ Cifras obtenidas del us Department of Commerce, Survey of Current Business, Washington, varios números.

${ }^{16}$ Este argumento también se sostiene con claridad en artículos crecientes como David Hale, "On an investment collision course", The Wall Street fournal, enero 24,1985, p. 1 .
} 
el de Japón, potencia que le sigue en importancia, y cerca de 5 veces mayor que el de Alemania, país con la mayor base productiva de Europa Occidental ${ }^{17}$.

La magnitud del espacio económico norteamericano y su dinámica, junto con su liderazgo indiscutido en la investigación básica, son dos factores suficientes para afirmar que la economía norteamericana estará en el centro de la nueva fase de industrialización y de avance tecnológico contemporáneo.

A partir de 1983 se rompió la tendencia de baja productividad y escasa tasa de inversión. El incremento de la productividad (medido como el aumento de producción por hora-hombre en porcentaje y tasa anual), mostró una elevación a partir de 1983. Con fines comparativos conviene señalar que entre 1960 y 1969 el incremento medio de productividad fue de 2,9 por ciento anual. Luego esa tasa disminuyó al 1,6 por ciento en el período 1970-1974 y al 1,9 por ciento anual en el periodo 1975-1979. En 1980 y hasta 1982, debido a la recesión, la tasa de incremento de la productividad fue bastante reducida $(-0,5$ por ciento en $1980 ; 1,9$ en 1981 y 0,2 por ciento en 1982). En 1983 se incrementó en 2,7 por ciento y en 1984 de 3,6 por ciento ${ }^{18}$.

$\mathrm{Y}$ también aumentaron las adquisiciones de bienes de capital para inversión. La compra de equipos, como porcentaje del producto nacional bruto de Estados Unidos, se elevó de 7,5 por ciento en el primer trimestre en 1983 , al 9,3 por ciento en el último trimestre de $1984^{19}$.

Aunque estos hechos son positivos, el periodo transcurrido es muy breve para augurar una recuperación de la posición de Estados Unidos en la producción, la inversión y la tecnología. Tres años no permiten proyectar una tendencia.

Es normal que la productividad acuse una elevación en periodos de recuperación, especialmente cuando tales periodos han sido precedidos por un fuerte crecimiento de la desocupación, como ocurrió a partir de 1979. Por otro lado, las condiciones financieras - tasa de interés alta y sobrevaloración del dólar- provocaron distorsiones en el proceso de inversión en Estados Unidos. Numerosos recursos se volcaron a bienes raíces y a la automatización del sector de servicios y bienes no transables.

Algunos analistas norteamericanos han destacado que los incrementos de la inversión no deben ser tomados como indicador direc-

\footnotetext{
${ }^{17}$ Banco Mundial, Informe sobre el desarrollo mundial, 1985, Washington, 1985, Guadro 1, p. I99.

${ }^{18}$ Cifras de The Economic Report of the President, 1985, Washington, cuadro B- 41, p. 279.

10Ibídem.
} 
to de mejoramiento de la base productiva ${ }^{20}$. La inversión de bienes no transables tiene ventajas comparativas, en cambio, la inversión en la base productiva, abierta a la competencia es más arriesgada. De mantenerse esta disparidad, podría desembocarse en una situación donde la base productiva se mantenga debilitada en las industrias maduras y posea una alta modernidad en el sector inmobiliario y en servicios que abastecen el consumo interno.

También subsiste una situación de deterioro de la infraestructura, Existe un atraso en las obras públicas ${ }^{21}$. Igual cosa ocurre en la educación, donde el cuadro no se ha alterado en el periodo reciente ${ }^{22}$.

En las manufacturas tradicionales no ha mejorado la situación de la industria norteamericana. En los años de expansión, ciertos sectores se han deteriorado más. Es cierto que existen innovaciones significativas en algunos rubros, para contener la penetración de productos externos $y$ es posible que en el futuro el ingreso de esos productos se contenga. En efecto, hay antecedentes que muestran que la penetración de productos extranjeros ha sido un fuerte estímulo para la investigación y modernización de la base productiva en numerosas industrias. Pero no es menos cierto que el incremento espectacular de las importaciones norteamericanas, mientras las exportaciones tienen un comportamiento relativamente estático, revelan una pérdida de competitividad y de capacidad de producción.

El debate sobre la política industrial que tomó cuerpo a comienzos de los ochenta-refleja esa preocupación. Se mencionaba entonces que dejar libradas las decisiones a las fuerzas del mercado era una desventaja respecto de la política de selección estratégica de Japón y Europa Occidental. Ese debate declinó en los años recientes, debido al incremento del producto y a la disminución de la cesantía en Estados Unidos. Sin embargo, los problemas siguen presentes.

Las consecuencias de esta pérdida de competitividad internacional ya se manifiestan en el campo político. El jefe de la mayoría de la Cámara de Diputados, Thomas O'Neill Jr., así lo mencionó en septiembre de 1985: "the heartland of America has been hurt terrifically. Anything we have out there with regard to protectionism will pass right through"23. El senador Lloyd Bentsen también expresaba: "The us government is sitting and watching this country manufacturing capacity being dismantled brick by brick" 24

En las actividades de tecnología avanzada, Japón continuará su

${ }^{20}$ David Hale, op. cit.

${ }^{21}$ Congressional Budget Office, Public Work Infrastructure. Policy Considerations for the eighties. Washington, abril 1983.

The National Commission on Excellence in Education. A Nation at Risk: the Imperative for Educational Reform, Washington, abril 1983.

${ }^{2}$ The New York Times, septiembre 1985, p. E-5.

2*The New York Times, julio 21 de 1985. 
expansión, disputando con Estados Unidos. La política industrial japonesa para el año 2000 revela la decisión estratégica de mantener e incluso asumir liderazgo en nuevos sectores.

Los países europeos han tenido una reacción más lenta. Su capacidad de concertación es limitada por los intereses contrapuestos entre naciones de la Comunidad. Con todo, han articulado proyectos conjuntos, como Arianne, AirBus y los programas recientes SPRIT, EUREKA. Asimismo, han tomado decisiones para preservar cierta autonomía en la investigación espacial y en el diseño de nuevas armas, respecto de la iniciativa de defensa estratégica de Estados Unidos.

En lo que concierne a patses en desarrollo y, en particular a los de industrialización reciente (NICS), la situación financiera y la necesidad de mantener ritmos de crecimiento alto los obligará a elevar sus exportaciones de manufacturas. Este fenómeno también presionará sobre las industrias tradicionales norteamericanas.

La emergencia de China al mercado internacional y la eventual realización de reformas económicas en la Unión Soviética son hechos que podrían modificar la distribución de poder económico internacional.

Estados Unidos mantendrá el liderazgo en la investigación básica. Este liderazgo se sustenta en buena medida en el gasto militar, que ha alcanzado en 1984 la suma de 350 mil millones de dólares. Casi el 50 por ciento de la investigación norteamericana está siendo financiada por el presupuesto militar. Esta forma de financiamiento es un apoyo significativo para la investigación, pero al mismo tiempo condiciona su orientación y la capacidad de transferir esas innovaciones a los bienes de consumo y de capital para la producción pacífica ${ }^{25}$.

En conclusión, pienso que en el comercio, la innovación tecnológica y la base productiva Estados Unidos sexá un lider en la división internacional del trabajo en curso. Sin embargo, su posición será crecientemente disputada. La declinación de Estados Unidos en las últimas décadas no se ha revertido en los años recientes. Esta recuperación hegemónica reciente se ha dado más en el terreno financiero que en el campo productivo y tecnológico.

\section{Hegemonía económica y seguridad militar}

La capacidad de imponer sus criterios económicos ha dependido también de la política militar de Estados Unidos. Al igual que en el terreno económico, la administración Reagan actuó resueltamente en el campo estratégico y determinó una línea de comportamien-

\footnotetext{
"Kenneth Flamm, "Política industrial y ajuste estructural", en SELA, La politica económica de Estados Unidos y su impacto en América Latina. Caracas, octubre 1984 .
} 
to que no ha dejado espacio para la negociación. Tambien aquí ha impuesto su criterio y ha obligado a los demás a acomodarse.

Esta resolución ha sido un factor importante para afirmar la preeminencia norteamericana en el sistema financiero internacional, ha coadyuvado a la fortaleza del dólar y también a la atracción de capitales de los demás países desarrollados y en desarrollo.

La política militar ha tenido otros efectos sobre la economía que han favorecido la recuperación hegemónica. En el terreno internacional, ha amparado al despliegue económico de Japón y de los países del Sudeste Asiático. El paraguas de defensa estratégica norteamericana en esa zona, ha creado un espacio de expansión y una relación más estrecha entre Estados Unidos y sus aliados del área.

La insistencia del gobierno de Reagan de colocar misiles nucleares en Europa obligó a los países europeos a adoptar una actitud más cautelosa y apoyar o aceptar la política norteamericana. Por su parte, las presiones sobre los europeos para que eleven el gasto en defensa ha tenido como contrapartida de éstos una actitud más medida hacia Estados Unidos en otras materias económicas.

La postura estratégica norteamericana ha creado la sensación de relativa seguridad para la diversificación económica, la expansión del sistema financiero, comercial y tecnológico entre los países más avanzados. También el gasto militar ha constituido un respaldo importante para el llamado complejo militar industrial, sirviendo como activador de la producción, la inversión y el gasto en investigación básica y aplicada, permitiéndole a Estados Unidos mantenerse en la punta del conocimiento en las áreas más avanzadas.

Entre economía y seguridad, también hay una relación positiva, en cuanto los factores económicos han reforzado el poder estratégico norteamericano. Uno de los vínculos importantes ha sido la capacidad económica norteamericana para elevar el gasto militar con recursos provenientes del exterior. La compra masiva, por ejemplo, de bonos del Tesoro de Estados Unidos por parte de Japón y Europa, sin contar con fondos provenientes de países petroleros y de países latinoamericanos, ha permitido a Estados Unidos compatibilizar expansión militar, recuperación económica, dólar fuerte y así mantener su predominio en el aparato financiero.

Otro vínculo importante entre economía y seguridad es el desarrollo de una economía mundial regulada por Estados Unidos y los principales países desarrollados. El incremento sustancial de la interdependencia económica y la creciente vulnerabilidad de los países del Tercer Mundo, les ha restado margen de maniobra.

De este modo, la expansión de las relaciones económicas y la creación de un sistema más denso de vínculos entre las naciones, especialmente de las medianas y pequeñas con el sistema financiero, comercial y de inversión internacional, han constituido una suerte 
de "red de seguridad" para Estados Unidos. 'Los países del Tercer Mundo se encuentran más limitados para realizar cambios internos de estructura y de poder si ellos provocan una alteración mayor de sus relaciones económicas internacionales. Es difícil imaginar la supervivencia de un gobierno que rompe lazos económicos externos, especialmente en países de desarrollo mediano, con sociedades civiles complejas.

El propio Fidel Gastro ha planteado nuevas ideas en esta materia, llegando a señalar que es más importante la formación de un frente externo común de los países latinoamericanos para modificar el orden económico internacional que llevar a cabo una, dos o tres revoluciones aisladas ${ }^{26}$.

Esta red de seguridad tiene importancia estratégica para Estados Unidos, por cuanto la disputa Este-Oeste en el Tercer Mundo dejarfa a ese país con una ventaja adicional: control de la economf́a mundial donde están insertos los países del Sur.

Una tercera relación entre economía y seguridad es la "batalla ideológica". Estados Unidos ha desatado una campaña sobre la superioridad de la economía de mercado frente a las economías centralizadas del socialismo real. Las dificultades económicas en la Unión Soviética y su rigidez en el terreno de la innovación y difusión tecnológica han sido tomadas como demostración de la inferioridad relativa de estos modelos como referencia para los países deI Tercer Mundo.

Debido al reforzamiento mutuo entre seguridad y recuperación hegemónica, una alteración de la imagen de seguridad de Estados Unidos podría afectar su hegemonía económica. EI hecho principal en materia estratégica es que, ante la imposibilidad de dirimir el conflicto Este-Oeste con el uso de armas nucleares que aniquilarían a la humanidad, este conflicto seguirá emergiendo en puntos localizados del Tercer Mundo.

Las relaciones entre las dos grandes potencias militares se han deteriorado, y el propio Gorbachov, en la entrevista mencionada de la revista Time señala: "relations between our two countries are continuing to deteriorete, the arms race is intesitying and the world threat is not subsiding" ${ }^{27}$.

La reaparición de conflictos localizados que no pudieran ser soIucionados por las grandes potencias militares y económicas podrfa debilitar la sensación de estabilidad y de hegemonía económica de Estados Unidos.

El problema del poder es también una cuestión psicológica y, en un mundo con un sistema financiero donde buena parte de los re-

"Ver Sergio Bitar, "Castro cambiarfa su política hacia América Latina". El Diario de Caracas, 9 de septiembre de 1985.

${ }^{2}$ Time, septiembre 29, 1985, p. 13. 
cursos están colocados a corto plazo y pueden movilizarse abruptamente en distintas direcciones, la percepción de inestabilidad puede amplificarse considerablemente, afectando el funcionamiento de la economfa global.

\section{Hegemonia y psicologia}

Cuando el paso de una situación de desánimo (acompañada de una percepción de decadencia) a una de optimismo (acompañada de una percepción de recuperación de poder), ocurre en un plazo tan breve, no puede ser atribuido puramente a factores económicos. Los fenómenos económicos requieren de períodos más prolongados para manifestarse con solidez. Es probable, por tanto, que en este cambio hayan tenido mucha influencia elementos de índole psicológica.

El poder se funda en la capacidad de ejercer la fuerza militar, económica, moral, etc. Pero la percepción del poder es en si un factor de poder y esa percepción puede agrandarse o reducirse mediante distintas acciones, recursos, propagandas, ideologías, medios de comunicación, etc., sin haber alterado las bases reales del poder.

En el campo económico y en el militar la administración Reagan ha tenido particular habilidad para demostrar decisión. Ha sido inflexible para mantener su política económica nacional e internacional. También ha sido dura para actuar en Centroamérica, al punto de invadir una pequeña isla como Granada, para mostrar su decisión de proceder con firmeza.

Contribuye a proyectar esta imagen de fortaleza la apariencia de debilidad de los demás. Así, por ejemplo, la proyección de una Unión Soviética "rígida" en lo económico y "perversa" en lo político, disminuye su significado a los ojos de otros actores políticos. Asimismo, la proyección de una Europa "esclerótica", de un Japón "dependiente" comercial y militarmente de Estados Unidos, y de una América Latina "impotente" para modificar la situación de explotación, acrecienta la imagen de fortaleza de Estados Unidos. Estos factores influyen sobre la economía. La fortaleza del dólar, por ejemplo, tiene poca justificación si se analiza exclusivamente en términos económicos.

Dentro de Estados Unidos la debilidad del Partido Demócrata también ha contribuido al auge de la Administración Reagan. Este partido se ha visto incapaz de proponer alternativas de gobierno $y$ ha visto debilitarse sus posibilidades presidenciales. Las alianzas que le dieron sustento en el pasado ya no parecen suficientes por los cambios sociales y de comportamientos acaecidos en la sociedad norteamericana.

Gabe preguntarse thasta dónde esta situación depende de la personalidad del Presidente Reagan? Aunque difícil de cuantificar, esta recuperación del poder norteamericano se ha apoyado en un 
hombre con una enorme capacidad de comunicación de masas, en un momento de la historia contemporánea, cuando los medios de comunicación social se han extendido de una manera no antes conocida.

Encuestas recientes revelan un gran optimismo en el pais y en el gobierno de Reagan. Así, por ejemplo, una realizada por The New York Times y la compañía de televisión CBs News, en enero de 1985, reveló que un 68 por ciento de los norteamericanos consideraba que se estaba mejor o igual que hace cinco años, y solamente un 26 por ciento afirmaba encontrarse peor. Ante la pregunta de cómo sería la situación en cinco años más, un 70 por ciento afirmó que sería igual o mejor y sólo un 21 por ciento, inferior ${ }^{28}$.

Thomas O'Neill, jefe de la oposición en la Cámara de Diputados, expresó a Reagan en enero de 1985: "In my fifty years of public life, I have never seen a man more popular than you with the American people"29.

Otros estudiosos de la política norteamericana han expresado: "An analysis of preelectoral polls and the election returns themselves makes clear that voters liked Reagan's patriotism and his emphasis on American strenght and even rearmament"30.

Existe una conexión entre ánimo exitista y personalidad del lfder. Podría entonces indagarse sobre las consecuencias resultantes de un cambio de Presidente en Estados Unidos. La propia operación que sufriera Reagan hace un tiempo incidió sobre algunas variables económicas, como la tasa de cambio.

Junto a esta sensación de éxito y de seguridad, las encuestas también revelan que los norteamericanos perciben hostilidad de parte de otros países del mundo. Las manifestaciones en las Filipinas contra Marcos, vinculándolo con los norteamericanos; la actitud antinorteamericana de los iraníes que apoyan al régimen de Khomeini; las manifestaciones del Medio Oriente y la reciente toma de rehenes de un avión en Beirut para exigir que los norteamericanos presionaran a Israel para liberar a prisioneros musulmanes shiitas, los movimientos pacifistas de Europa Occidental, las manifestaciones de hostilidad provenientes de amplios sectores de América Latina, son captadas en Estados Unidos y constituyen la otra cara de la medalla.

Es cierto que la política norteamericana cuenta con el respaldo de sectores de las finanzas internacionales, de sectores de ingresos altos y capas medias de los países desarrollados y de paises en desa-

${ }^{23}$ The New York Times, 27 enero 1985.

Según The New York Times, enero 27, 1985, O'Neill habrfa expresado esa frase a Reagan en privado.

${ }^{30}$ Henry Grunwald, "Foreign Policy Reagan Ir", Foreign Affairs, winter 19841985, p. 237. 
rrollo. Pero también es cierto que existen focos de descontento que se dirigen contra ese país.

La hegemonía y la psicología tienen una relación y, por tanto, una alteración del ánimo y de las actitudes tendrá incidencia en la posición de Estados Unidos. Un liderazgo por parte de ese país exigirá una concertación más extensa con otros países que en el pasado reciente.

\section{La hegemonia de Estados Unidos desde la perspectiva latinoamericana}

Desde América Latina la recuperación del poder norteamericano se ve con lente de aumento. Las apreciaciones globales asumen un carácter más acentuado, porque en la relación entre Norteamérica y América Latina, la primera ha tenido un auge apreciable en relación a las tendencias pasadas, mientras la segunda ha sufrido una caida significativa.

En los años recientes, nuestra región ha acusado un considerable incremento de vulnerabilidad frente a Estados Unidos. En el campo bancario, América Latina ha perdido importancia para Estados Unidos. En 1984, las colocaciones de la banca norteamericana en los principales países de América Latina alcanzaron a 83 mil 400 millones de dólares, mientras que el total de las colocaciones internacionales de la banca norteamericana a fines de ese año, alcanzaron 614,500 millones de dólares, es decir. América Latina representó el 13,6 por ciento del total ${ }^{31}$.

El riesgo para los nueve mayores bancos de Estados Unidos también decreció. Las colocaciones en nuestra región, como porcentaje del capital de esos nueve bancos, alcanzó al 135 por ciento en 1978, subió al 175 por ciento en 1981 y volvió a descender a 140 por ciento en $1984^{32}$.

Para América Latina, en cambio, la importancia financiera de Estados Unidos se acentuó. Las deudas de los ocho padses mayores de la región con bancos norteamericanos alcanzaron al 36 por ciento de las deudas con el sistema bancario internacional, a fines de $1984^{33}$.

En el comercio ocurrió lo mismo; también América Latina perdió importancia para Estados Unidos. En 1980, la región representaba para ese país, el 17 por ciento de sus exportaciones; en 1984

${ }^{31}$ Cálculos basados en Morgan Guaranty Trust, World Financial Market, julio 1985, Cuadro 2, p. 5 y Cuadro 4, p. 7. Las citras para América Latina corresponden a Argentina, Brasil, Colombia, Ecuador, Chile, Perú y Venezuela.

3oTbid, gráfico 2, p. 9.

${ }^{*}$ Secretarfa Permanente, SELA, América Latina-Estados Unidos: evolución de las relaciones económicas, 1984-1985, septiembre de 1985, Caracas, cuadro 22, p. 97 y cuadro 23, p. 99. 
nuestra región absorbió sólo el 13,1 por ciento. En cuanto a las importaciones realizadas por los norteamericanos, en 1980 el 15,2 por ciento provino de América Latina; en 1984, esa cifra habia descendido a 14,7 por ciento. Por primera vez en la historia, el Sudeste Asiático y el Japón, cada uno separadamente, sobrepasaron a América Latina como fuente de abastecimiento de importaciones para Estados Unidos ${ }^{34}$.

A la inversa, Estados Unidos elevó desproporcionadamente su importancia para América Latina como mercado para sus exportaciones y como proveedor de importaciones. En 1970, aproximadamente el 35 por ciento de las exportaciones latinoamericanas se colocaron en el mercado norteamericano, en 1980 la proporción ascendió al 40 por ciento del total y esta cifra se elevó al 49 por ciento en 1984. Un hecho similar aconteció en las importaciones de la región provenientes de Estados Unidos. Estas evolucionaron desde un 40 por ciento en 1980 al 46,4 por ciento del total regional en $1984^{35}$.

Nunca antes, desde la década de los cincuenta, se había verificado un desequilibrio de esta magnitud entre Estados Unidos y América Latina.

En la inversión extranjera directa las tendencias son similares. La importancia de América Latina se redujo para los Estados Unidos. En 1970, las inversiones norteamericanas en la región representaban el 14,7 por ciento de las inversiones norteamericanas en el mundo y en 1983 esa cifra había bajado a 12,8 por ciento ${ }^{36}$. Para América Latina, en cambio, las inversiones extranjeras norteamericanas han continuado siendo durante todo este período cerca del 60 por ciento del totali37.

A este desequilibrio se agrega otro hecho nuevo: la tremenda incidencia de las decisiones monetarias y fiscales norteamericanas sobre la política macroeconómica latinoamericana. Las variaciones de Ias tasas de interés y del valor del dólar respecto de las demás monedas han tenido un efecto considerable sobre la situación fiscal y de comercio externo de la región. Resulta muy difícil diseñar una política económica sin tener en cuenta la repercusión de los fenómenos originados en la economía norteamericana.

A mediados de los ochenta, la región se encuentra en una situa-

\footnotetext{
${ }^{8}$ Secretaría Permanente, SELA, América Latina-Estados Unidos: evolución de las relaciones económicas 1984-1985, septiembre 1985, Caracas, cuadro 22, p. 97 $\mathrm{y}$ cuadro 23, p. 99.

${ }^{a ̆}$ SELA, op. cit., p. 98.

${ }^{20}$ Sergio Bitar, "La polftica de inversiones de Estados Unidos. Implicaciones para América Latina", SELA, doc. interno, Caracas, agosto, 1985.

${ }^{a}$ Sergio Bitar, "Corporaciones transnacionales y las nuevas relaciones de América Latina con Estados Unidos", en Economia de América Latina, primer semestre 1984, México, cuadro 3, p. 103.
} 
ción de vulnerabilidad marcada. Las tendencias a la desvinculación comercial con Estados Unidos, a la diversificación de los mercados financieros y de sus inversiones extranjeras, que ocurrieron hasta comienzos de los ochenta, se han modificado considerablemente.

Pienso que esta situación distorsionada no se mantendrá en este nivel y se irá corrigiendo progresivamente. Pero también estimo que no se recuperarán los niveles de autonomía relativa de la región, existentes en 1980, a la misma velocidad con que se deterioraron.

Para evaluar el impacto de esta alteración sobre el margen de maniobra latinoamericano es necesario distinguir entre el poder de regulación global de Estados Unidos y lo que es su poder económico de control directo, a través de mecanismos bilaterales.

Estados Unidos ha incrementado su capacidad de regulación del sistema y esa es su prioridad estratégica. Este hecho se hace sentir sobre la región, la cual se ve entrabada por el sistema financiero y comercial internacional y coaccionada por el FMa, que responde a criterios norteamericanos.

Sin embargo, también América Latina posee un grado de maniobra adicional en la medida que ha disminuido la capacidad de control bilateral de Estados Unidos. Esto último deja un espacio disponible para cambios nacionales.

El análisis de esta situación global conduce a una conclusión fundamental: América Latina está obligada a actuar concertadamente para hacer frente a este nuevo cuadro internacional.

Es imprescindible llevar a cabo una evaluación permanente de los factores que determinan la posición relativa de los Estados Unidos frente a los demás actores económicos internacionales y de los hechos que pueden provocar un debilitamiento de su posición hegemónica. Las tensiones y conflictos abrirán espacios que permitirán presionar para que los intereses de los marginados en la economía mundial sean incorporados de una manera menos desequilibrada e injusta. 